\title{
UNIVERSITYOF
}

FORWARD

THINKING

WESTMINSTER用

WestminsterResearch

http://www.westminster.ac.uk/westminsterresearch

Identification of the splice variants of Recepteur d'Origine nantais (RON) in lung cancer cell lines

Krishnaswamy, S., Bukhari, I., Mohammed, A.K., Amer, O.E., Tripathi, G., Alokail, M.S. and Al-Daghri, N.M.

NOTICE: this is the authors' version of a work that was accepted for publication in Gene. Changes resulting from the publishing process, such as peer review, editing, corrections, structural formatting, and other quality control mechanisms may not be reflected in this document. Changes may have been made to this work since it was submitted for publication. A definitive version was subsequently published in Gene, 679, pp. 335-340, 2018.

The final definitive version in Gene is available online at:

https://dx.doi.org/10.1016/j.gene.2018.09.027

(C) 2018. This manuscript version is made available under the CC-BY-NC-ND 4.0 license https://creativecommons.org/licenses/by-nc-nd/4.0/

The WestminsterResearch online digital archive at the University of Westminster aims to make the research output of the University available to a wider audience. Copyright and Moral Rights remain with the authors and/or copyright owners.

Whilst further distribution of specific materials from within this archive is forbidden, you may freely distribute the URL of WestminsterResearch: ((http://westminsterresearch.wmin.ac.uk/)).

In case of abuse or copyright appearing without permission e-mail repository@westminster.ac.uk 


\section{Identification of the Splice Variants of Recepteur d'Origine nantais (RON) in Lung Cancer

\section{Cell Lines}

3

4 Soundararajan Krishnaswamy ${ }^{1,2 \#}$, Ihtisham Bukhari ${ }^{1,2 \#}$, Abdul Khader Mohammed ${ }^{1,2}$, Osama

5 Emam Amer ${ }^{1,2}$, Gyanendra Tripathi ${ }^{3}$, Majed S. Alokail ${ }^{1,2}$, Nasser M. Al-Daghri ${ }^{1,2^{*}}$

6

$7 \quad{ }^{1}$ Biomarkers Research Program, Biochemistry Department, College of Science, King Saud

8 University 11451, Riyadh, Saudi Arabia.

9 2Prince Mutaib Chair for Biomarkers of Osteoporosis, Biochemistry Department, College of

10 Science, King Saud University 11451, Riyadh, Saudi Arabia.

$11{ }^{3}$ Department of Biomedical Sciences, University of Westminster, London W1W 6UW, UK.

12 \# Authors contributed equally to this work

13 Emails:

14 Soundararajan Krishnaswamy: ksounder@gmail.com

15 Ihtisham Bukhari: bukhari5408@gmail.com

16 Abdul Khader Mohammed: makhaderonline@gmail.com

17 Osma Emam Amer: osamaemam@gmail.com

18 Gyanendra Tripathi: g.tripathi@westminster.ac.uk

19 Majed S. Alokail: msa85@yahoo.co.uk

20 Nasser M. Al-Daghri: aldaghri2011@gmail.com

$21 *$ Corresponding Author:

Nasser M. Al-Daghri, Ph.D

22

23

24

25

26

27

28

Prince Mutaib Bin Abdullah Chair for Osteoporosis, Biochemistry Department, College of Science, King Saud University, PO Box, 2455, Riyadh 11451, Saudi Arabia.

Tel.: 0096614675939

Fax: 0096614675931

29 


\section{Abstract}

31 RON receptor tyrosine kinase is a transmembrane protein directly involved in suppression of

32 inflammation and its aberrant expression linked to cancers and metastasis. Efforts to block

33 deregulated RON signaling in tumors using small molecule kinase inhibitors or antibodies have

34 been complicated by the presence of unknown number/types of isoforms of RON, which, despite

35 being structurally similar, localize differently and mediate varied functions. Current study was

36 designed to identify the splice variants of RON transcripts formed by skipping of sequences

37 between exons 9 and 14 for better understanding of isoform specific RON signaling in cancers.

38 PCR amplification and bi-directional sequencing of a 901bp cDNA sequence located between

39 exons 9 to 14 of RON from lung cancer cell lines revealed the presence of two splicing variants

40 formed by skipping of exons 11 and 11-13. Each of these transcripts was found in more than one

41 cell line. Expressed sequence tag (EST) database search indicated that the splicing variant lacking

42 exons 11-13 was a novel one. Here we conclude that the splice variants of RON lacking exon 11

43 and exons 11-13 were detected in several lung cancer cell lines. Novel variant formed by skipping

44 exons 11-13, the sequence of which code for transmembrane region, is predicted to code for a

45 truncated isoform that may be secreted out. Tumors may antagonize the ligand dependent anti-

46 inflammatory function of wild-type RON by secreting out the ligand binding isoforms.

47 Keywords: alternative splicing; lung cancer; macrophage stimulating protein (MST1R); receptor

48 tyrosine kinase; RON; RON isoform 


\section{Introduction}

52 RON, also known as MST1R (macrophage-stimulating 1 receptor), is a member of the MET family

53 of receptor tyrosine kinases (RTKs). MSP (macrophage stimulating protein, the ligand for RON)

54 driven RON signaling has been shown to be anti-inflammatory via many models (Correll et al.,

55 1997; Liu et al., 1999; Waltz et al., 2001). MSP/RON signaling is activated in macrophages

56 following acute inflammation and serves to suppress synthesis of pro-inflammatory mediators like

57 nitric oxide (NO), prostaglandins and several other pro-inflammatory cytokines and upregulate

58 anti-inflammatory cytokines like IL-10 (Gunella et al., 2006). RON activation also blocks NF-

59 kappaB activation (Zhou et al., 2002), and further is a critical determinant of macrophage

60 activation states (M1/M2) (Sharda et al., 2011).

61 Ample evidence indicate deregulated expression and functioning of RON in a number of cancers

62 (Gaudino et al., 1995; Wang et al., 1996; Sakamoto et al., 1997; Maggiora et al., 1998; Wang et

63 al., 2000; Camp et al., 2007; Zhou et al., 2008; Kretschmann et al., 2010). While RON

64 overexpression is associated with tumor aggressiveness and metastasis (Thomas et al., 2007),

65 knockdown of RON expression in different cancer cell lines using siRNA/shRNA showed

66 suppression of tumorigenic properties (Xu et al., 2004; Wang et al., 2009; Logan-Collins et al.,

67 2010). Validation of overexpressed RON as a therapeutic target in tumors has been hampered due

68 to the simultaneous production of its several isoforms. Previously, protein expression analyses

69 indicated the absence of wild type RON but its isoforms present in lung cancer cell lines could not

70 be detected with Western blotting (Kanteti et al., 2012). Several variant transcripts and their protein

71 products have been described for RON in various cancer cell lines as well as solid and pleural

72 tumors (Lu et al., 2007). Despite exhibiting diverse functions in cancers, the isoforms show

73 considerable sequence similarity and to the wild type RON. The isoforms include both active 
74 (Wang et al., 2000; Angeloni et al., 2007; Zhou et al., 2008) as well as various N-terminally

75 truncated dominant negative variants (Lu et al., 2007; Jin et al., 2008; Eckerich et al., 2009; Ma et

76 al., 2010). Ectopic expression of some RON splice variants in NIH3T3 cells induced tumor

77 formation in vivo (Zhou et al., 2003).

78 We hypothesize that aberrant expression of RON via alternative splicing in cancers may alter its anti-

79 inflammatory role and hence structural and functional characterization of the individual isoforms may

80 elucidate their role in cancer development. Recently, we reported the presence of several, frequently

81 occurring novel transcript variants affecting the intracellular region of RON in lung cancer cell lines

82 (Krishnaswamy et al., 2015; Krishnaswamy et al., 2016). In this study, we focused on RON mRNA

83 sequence between exons 9 and 14 to identify any novel splicing variants, using various lung cancer

84 cell lines, by PCR amplification and sequencing.

\section{Materials and Methods}

$86 \quad$ Cell lines

87 SCLC cell lines H526, H446, H249, H69, H2171, H345, H82, H146, H889 and H524 and

88 NSCLC cell lines SW1573, H358, A549, H1838, H661, H522, H1437, H2170, SW900, H1993,

89 SKLU-1, H1703 and SKMES were obtained from ATCC (Manassas, VA) and were cultured in

90 RPMI 1640 medium (Gibco/BRL) supplemented with 10\% (v/v) fetal bovine serum supplemented

91 with L-glutamine and $1 \%(\mathrm{v} / \mathrm{v})$ penicillin/streptomycin at $37^{\circ} \mathrm{C}$ with $5 \% \mathrm{CO}_{2}$.

\section{2 cDNA preparation, PCR and sequencing}

93 Total RNA from the cell lines was isolated using TRIZol reagent (Invitrogen, Carlsbad, CA, USA)

94 following manufacturer's instructions. cDNA was generated using $1 \mu \mathrm{g}$ of total RNA and oligo dT

95 primer by using Single Strand cDNA Synthesis Kit (Clontech, Palo Alto, CA, USA). cDNAs of 96 RON were amplified thermal cycler using specifically designed primers covering $901 \mathrm{bps}$ of RON 
97 reference mRNA sequence (NM_000247) using forward primer (located in exon 9) 5'-

98 CAGCATCTAACTTCAGCATGGCACTTAG - 3' and reverse primer (located in exon 14) 5'-

99 CAGTGACCGAGTCATTGGCAAAG - 3'. Sequencing was performed in final volume of $10 \mu 1$.

100 BigDye ${ }^{\circledR}$ Terminator (V 3.1) Sequencing reactions were carried out by using 0.4 pmole of either

101 forward or reverse primers. The $10 \mu 1$ reaction consisted of $0.5-1 \mu 1$ of BigDye mix, $1.5 \mu 1$ of $5 \mathrm{X}$

102 sequencing buffer (Tris $\mathrm{HCl} 400 \mathrm{mM}$ pH 9, $\mathrm{MgCl} 210 \mathrm{mM}$ ) and 5-6 $\mu 1$ purified PCR product.

103 Sequencing PCR reaction mixes were initially denatured at 96C for 1 minute and 30 seconds,

104 followed by 35 cycles of denaturation at 96C for 45 seconds and annealing at 50C for 30 seconds,

105 and extension at 60C for 4 minutes. Sequencing PCR products ere purified and dissolved in $12 \mu \mathrm{l}$

106 Hi-DiTM formamide before loading on a genetic analyzer (Applied Biosystems PRISM 310,

107 Foster City, CA). Sequence variations in the PCR products were identified by aligning sequencing

108 chromatograms with reference RON sequence using Mutation Surveyor version 3.1 software

109 (SoftGenetics, State College, PA). The numbering of nucleotide positions is relative to the first 110 base of the translational initiation codon of the full-length RON coding sequence (CCDS 2807.1).

\section{Results}

112 A number of alternatively spliced forms of RON mRNA and their protein products have previously

113 been reported. However, amplifying the entire coding sequence of RON (4200 bps) as a single

114 amplicon and sequencing would have failed to provide a complete picture of all the alternative 115 splicing events due to the formation of multiple products possessing largely similar sequences. 116 Hence, we amplified a short section of RON mRNA, covering region between exons 9 and 14, by 117 converting to cDNA and using forward and reverse PCR primer sequences located in exons 9 and 118 14, respectively (Figure 1). Sequence chromatograms were obtained using the forward 119 amplification primer for NSCLC cell line H661 indicated the presence of a predominant variant 
120 lacking exon 11 (Figure 2). This splicing variant was also found in A549, SKLU1, A249, H69, 121 H82, H345 and H526 cell lines.

122 Chromatograms of cell line H249 were obtained by sequencing from $5^{\prime}$ end indicated the co123 occurrence of two splice variants, one formed by skipping of exon 11 and the other formed by 124 skipping of exons 11-13. Further, exon 10 of the major variant (based on peak heights) ended with 125 TTTTAG sequence, while it ended with TTT in the minor variant due to the deletion of the last 126 three (TAG) nucleotides. Two additional overlapping new sequences starting at nucleotide 2650 127 (of RON reference sequence) were also identified; these sequences corresponded to starting 128 nucleotides of exons 12 and 14, identifying them as distinct splicing variants arising from the loss 129 of exon 11 and exons 11-13, respectively. Exon 11 containing wild type/reference RON transcript 130 sequence was completely missing from H249 PCR products. Skipping of exon 11 results in an in131 frame deletion of 147 nucleotides, corresponding to 49 amino acids, and skipping of exons 11-13 132 leads to loss of 415 nucleotides and consequently a frame-shift leading to the appearance of 133 premature termination codon. RON splicing variant lacking exons 11-13 was also found in H358, 134 H146, H524, A549, SKLU1, SKMES, H69, H1703, H1993, H82, and H889 cell lines (Figure 3).

135 The overlapping of sequences started at nucleotide 3066 of RON reference sequence and the two 136 overlapping sequences matched with exons 10 and 13 of the reference sequence in H1993. This 137 confirmed the presence of the splicing variant formed by loss of exons 11-13, which occurred 138 along with the wild-type transcript. Furthermore, from the size of the peaks, alternatively spliced 139 transcript variant was identified at a higher level than the wild-type transcript. In this cell line, only 140 the splicing variant whose exon 10 sequence ends with bases TTTGAG was found (Figure 4). 141 Intron sequence located between exons 9 and 10 was spliced out in two different ways in H1993 142 (Figure 5): the last three nucleotides of this intron (CAG) were retained in the minor (based on 
143 peak heights) splicing variant, while these nucleotides were not included in the major splicing

144 variant. The splicing variant that retained CAG at the beginning of exon 10 ended up losing the

145 last three nucleotides, GAG, of exon 10, as shown in H249 cell line (Figure 3).

\section{Discussion}

147 Aberrant expression of RON in tumors is accompanied by alternative splicing of mRNA transcripts

148 leading to expression of an array of isoform products having varying functions. However, high

149 level of sequence similarities among the transcript variants and their protein isoforms pose

150 problems in specific target discovery and validation. In this study, we screened lung cancer cell

151 lines for splicing variants between exons 9 and 14 of RON transcripts through partial cDNA

152 sequencing. Results revealed the presence of a novel alternatively spliced variant lacking exons

153 11-13 and a previously known variant formed by skipping of exon 11. Both these variants occurred

154 together in several cell lines. Both variants were found with or without deletion of the last three

155 nucleotides of exon 10, GAG, which codes for glutamic acid. This single codon difference between

156 transcript variants was created by differential splicing of exon 10. Exon 12 contains sequence

157 coding for transmembrane (TM) domain, and skipping of exons 11-13 leads to frame-shift and

158 appearance of premature termination codon. Translation product of transcript variant lacking

159 exons 11-13 is expected to be secreted and the produced isoform may block MSP/RON signaling

160 by binding to MSP or by dimerizing with normal RON, by making N-terminally truncated isoforms

161 of RON. Thus, tumors may nullify the anti-inflammatory/anti-carcinogenic role of MSP/RON

162 signaling via altering the splicing pattern of RON RTK.

163 Two RON transcripts involving differential splicing of exon 11 have been reported previously;

164 one of these lacked exons 5, 6 and 11 and the other lacked only exon 11. Skipping of exon 11

165 caused an in-frame deletion of 147 nucleotides, corresponding to 49 amino acids of the 
extracellular region of RON beta chain, resulting in RONdelta165, a constitutionally active

167 cytoplasmic isoform (Zhou et al., 2003; Lu et al., 2007). Transcript lacking exons 5, 6 and 11 was

168 translated into RONdelta155, a cytoplasmic isoform of RON that was also constitutively active

169 (Zhou et al., 2003; Lu et al., 2007). Partial splicing of exons 5 and 6 (P5P6) produces a RON

170 isoform that lacks the first extracellular immunoglobulin-plexin-transcription domain which

171 express in human pancreatic cancer (Chakedis et al, 2016). The expression of RON wildtype,

172 p165, p160, and p155 transcripts were studied in different cancer tissues. The higher expression

173 of RON transcripts was noted in lung, gastroesophageal, and colon tissues (both normal and

174 cancerous) than breast, prostate, and ovarian tissues (both normal and cancerous)

175 (Wortinger and Liu, 2008). We used an antibody specific for amino acids 531-690 of the

176 extracellular region of beta RON for Western blot analysis in NSCLC and SCLC cell lines but no

177 expression of RON was found.

178 RON splicing variant lacking exons 11-13 is the novel finding of this study. Defective splicing 179 reactions causing large deletions and appearance of early termination codons in mRNAs have been 180 reported to be degraded via non-sense mediated decay (NMD). Even though the deleted sequence 181 is large (415 nucleotides) and deletion of exons 11-13 result in appearance of early termination 182 codon, this transcript is not expected to undergo NMD; this is because alternatively spliced RON 183 transcript lacking exon 6, which acquires a premature early termination codon caused by frame184 shift, was shown to yield a viable isoform, RONdelta90 (Eckerich et al., 2009). Also, RONdelta85 185 was shown to be an N-terminally truncated isoform of RON formed due to retention of 49 bases 186 of intron 5 (lying between exons 5 and 6) and consequently undergoing a reading-frameshift (Ma 187 et al., 2010). We expect that the translation product of transcript variant lacking exons 11-13 may 188 be secreted extracellularly in a fashion similar to the two isoforms, RONdelta90 and RONdelta85. 
189 The isoform product coded by transcript variant lacking exons $11-13$ is predicted to act in a 190 dominant negative fashion and block MSP stimulated RON signaling, as in the case RONdelta85 191 and RONdelta90 (Eckerich et al., 2009; Ma et al., 2010). We speculate that the constitutively active 192 isoform, encoded by transcript lacking exon 11, and the dominant negative isoform, which may 193 serve to block ligand dependent RON signaling, together may enable tumors acquire ligand (MSP) 194 independent RON signaling.

195 One of the primary hallmarks of cancer is growth factor independent signaling. However, how 196 cancer cells achieve this is not yet understood and more research on dominant negative isoforms 197 produced by cancer cells may shed light on this aspect. Ubiquitous presence of RON isoforms 198 exhibiting dominant negative functions, such as the secreted ones capable of nullifying the effect 199 of ligand (MSP), truncated transmembrane or cytoplasmic isoforms capable of dimerizing with 200 wild type RON, in cancer also raises important questions regarding the appropriateness of targeting 201 wild type RON, which in fact may lead to tumors.

202 Identification and characterization of all the transcript variants and their protein products is 203 essential for RON target validation in cancer therapeutic development. Presence of alternatively 204 spliced transcripts lacking different coding regions in tumor cells is expected to interfere with 205 estimation of wild type RON expression, either by immunological or PCR methods, leading to 206 exaggerated values. Further, application of siRNAs, which usually lack transcript variant 207 specificity, may knockdown different transcripts affecting results of correlational studies (Celotto 208 and Graveley, 2002). In this context, several genes and their protein products have been found to 209 exert dual roles as tumor suppressors and stimulators, but the specific underlying mechanisms are 210 yet to be determined (Perkins, 2004; Krisenko and Geahlen, 2015). A complete understanding, at 211 a structural and functional level, of the various transcription products of RON is expected to lead 
212 to resolving the mechanism underlying their specific roles in cell signaling regulation and cancer

213 development and eventually help us to target its cancer specific signaling.

\section{Conclusion}

215 Tumors are normally screened for RON expression in target identification and validation studies.

216 Even though the functions of many of its isoforms may be different and even oppose each other in

217 some cases, current methods for quantification and functional analysis of RON cannot distinguish

218 between its isoforms. This study describes the identification of a novel alternatively splice site

219 sequence variant of RON that may affect its transmembrane localization. Sequence

220 characterizations presented here together with knowledge of previously identified isoforms point

221 to the need for design and application of isoform specific primers, siRNAs and antibodies for more

222 accurate isoform - functional correlational studies and the therapeutic development. Further,

223 inflammation is expected drive tumor development as well as metastasis and aberrant expression

224 of RON by tumors - via alternative splicing of transcripts - may attenuate its anti-inflammatory

225 functions.

\section{Availability of data and material}

227 The sequence reported in this paper has been deposited with the National Center for Biotechnology

228 Information (NCBI) Sequence Read Archive (SRA) (accession no. SRS354082).

\section{Competing interests}

230 All authors declare no competing interest.

\section{Authors' contributions}

232 SK and ND have made substantial contributions towards design, conceptualization, execution, 233 drafting and revision of the manuscript. AKM and OEA have helped with experimental part. IB 
and GT have thoroughly revised the MS. MSA has participated in analysis of data. All authors

have read and approved the final version of the manuscript for publication.

\section{Acknowledgements}

This project was funded by the National Plan for Science, Technology and Innovation (MAARIFAH), King Abdulaziz City for Science and Technology, Kingdom of Saudi Arabia (Award Number 11-MED-2086-02).

\section{References}

Angeloni, D., Danilkovitch-Miagkova, A., Ivanova, T., Braga, E., Zabarovsky, E. and Lerman, M.I., 2007. Hypermethylation of Ron proximal promoter associates with lack of full-length Ron and transcription of oncogenic short-Ron from an internal promoter. Oncogene 26, 4499-512.

Camp, E.R., Yang, A., Gray, M.J., Fan, F., Hamilton, S.R., Evans, D.B., Hooper, A.T., Pereira, D.S., Hicklin, D.J. and Ellis, L.M., 2007. Tyrosine kinase receptor RON in human pancreatic cancer: expression, function, and validation as a target. Cancer 109, 1030-9.

Celotto, A.M. and Graveley, B.R., 2002. Exon-specific RNAi: a tool for dissecting the functional relevance of alternative splicing. RNA 8, 718-24.

Chakedis, J., French, R., Babicky, M., Jaquish, D., Howard, H., Mose, E., Lam, R., Holman, P., Miyamoto, J., Walterscheid, Z., Lowy, A.M.. 2016. A novel protein isoform of the RON tyrosine kinase receptor transforms human pancreatic ductepithelial cells. Oncogene 35, 3249-59

Correll, P.H., Iwama, A., Tondat, S., Mayrhofer, G., Suda, T. and Bernstein, A., 1997. Deregulated inflammatory response in mice lacking the STK/RON receptor tyrosine kinase. Genes Funct 1, 69-83.

Eckerich, C., Schulte, A., Martens, T., Zapf, S., Westphal, M. and Lamszus, K., 2009. RON receptor tyrosine kinase in human gliomas: expression, function, and identification of a novel soluble splice variant. J Neurochem 109, 969-80.

Gaudino, G., Avantaggiato, V., Follenzi, A., Acampora, D., Simeone, A. and Comoglio, P.M., 1995. The proto-oncogene RON is involved in development of epithelial, bone and neuro-endocrine tissues. Oncogene 11, 2627-37.

Gunella, G., Bardelli, C., Amoruso, A., Viano, I., Balbo, P. and Brunelleschi, S., 2006. Macrophage-stimulating protein differently affects human alveolar macrophages from smoker and non-smoker patients: evaluation of respiratory burst, cytokine release and NF-kappaB pathway. Br J Pharmacol 148, 478-89.

Jin, P., Zhang, J., Sumariwalla, P.F., Ni, I., Jorgensen, B., Crawford, D., Phillips, S., Feldmann, M., Shepard, H.M. and Paleolog, E.M., 2008. Novel splice variants derived from the receptor tyrosine kinase superfamily are potential therapeutics for rheumatoid arthritis. Arthritis Res Ther 10, R73.

Kanteti, R., Krishnaswamy, S., Catenacci, D., Tan, Y.H., E, E.L.-H., Cervantes, G., Husain, A.N., Tretiakova, M., Vokes, E.E., Huet, H. and Salgia, R., 2012. Differential expression of RON in small and non-small cell lung cancers. Genes Chromosomes Cancer 51, 84151. 
Kretschmann, K.L., Eyob, H., Buys, S.S. and Welm, A.L., 2010. The macrophage stimulating protein/Ron pathway as a potential therapeutic target to impede multiple mechanisms involved in breast cancer progression. Curr Drug Targets 11, 1157-68.

Krisenko, M.O. and Geahlen, R.L., 2015. Calling in SYK: SYK's dual role as a tumor promoter and tumor suppressor in cancer. Biochim Biophys Acta 1853, 254-63.

Krishnaswamy, S., Mohammed, A.K., Amer, O.E., Tripathi, G., Alokail, M.S. and Al-Daghri, N.M., 2015. Recepteur d'Origine nantais (RON) tyrosine kinase splicing variants lacking exons 18 and 19 occur ubiquitously in lung cancer. Int J Clin Exp Med 8, 20778-86.

Krishnaswamy, S., Mohammed, A.K., Amer, O.E., Tripathi, G., Alokail, M.S. and Al-Daghri, N.M., 2016. Novel splicing variants of recepteur d'origine nantais (RON) tyrosine kinase involving exons 15-19 in lung cancer. Lung Cancer 92, 41-6.

Liu, Q.P., Fruit, K., Ward, J. and Correll, P.H., 1999. Negative regulation of macrophage activation in response to IFN-gamma and lipopolysaccharide by the STK/RON receptor tyrosine kinase. J Immunol 163, 6606-13.

Logan-Collins, J., Thomas, R.M., Yu, P., Jaquish, D., Mose, E., French, R., Stuart, W., McClaine, R., Aronow, B., Hoffman, R.M., Waltz, S.E. and Lowy, A.M., 2010. Silencing of RON receptor signaling promotes apoptosis and gemcitabine sensitivity in pancreatic cancers. Cancer Res 70, 1130-40.

Lu, Y., Yao, H.P. and Wang, M.H., 2007. Multiple variants of the RON receptor tyrosine kinase: biochemical properties, tumorigenic activities, and potential drug targets. Cancer Lett 257, 157-64.

Ma, Q., Zhang, K., Yao, H.P., Zhou, Y.Q., Padhye, S. and Wang, M.H., 2010. Inhibition of MSPRON signaling pathway in cancer cells by a novel soluble form of RON comprising the entire sema sequence. Int J Oncol 36, 1551-61.

Maggiora, P., Marchio, S., Stella, M.C., Giai, M., Belfiore, A., De Bortoli, M., Di Renzo, M.F., Costantino, A., Sismondi, P. and Comoglio, P.M., 1998. Overexpression of the RON gene in human breast carcinoma. Oncogene 16, 2927-33.

Perkins, N.D., 2004. NF-kappaB: tumor promoter or suppressor? Trends Cell Biol 14, 64-9.

Sakamoto, O., Iwama, A., Amitani, R., Takehara, T., Yamaguchi, N., Yamamoto, T., Masuyama, K., Yamanaka, T., Ando, M. and Suda, T., 1997. Role of macrophage-stimulating protein and its receptor, RON tyrosine kinase, in ciliary motility. J Clin Invest 99, 701-9.

Sharda, D.R., Yu, S., Ray, M., Squadrito, M.L., De Palma, M., Wynn, T.A., Morris, S.M., Jr. and Hankey, P.A., 2011. Regulation of macrophage arginase expression and tumor growth by the Ron receptor tyrosine kinase. J Immunol 187, 2181-92.

Thomas, R.M., Toney, K., Fenoglio-Preiser, C., Revelo-Penafiel, M.P., Hingorani, S.R., Tuveson, D.A., Waltz, S.E. and Lowy, A.M., 2007. The RON receptor tyrosine kinase mediates oncogenic phenotypes in pancreatic cancer cells and is increasingly expressed during pancreatic cancer progression. Cancer Res 67, 6075-82.

Waltz, S.E., Eaton, L., Toney-Earley, K., Hess, K.A., Peace, B.E., Ihlendorf, J.R., Wang, M.H., Kaestner, K.H. and Degen, S.J., 2001. Ron-mediated cytoplasmic signaling is dispensable for viability but is required to limit inflammatory responses. J Clin Invest 108, $567-76$.

Wang, J., Rajput, A., Kan, J.L., Rose, R., Liu, X.Q., Kuropatwinski, K., Hauser, J., Beko, A., Dominquez, I., Sharratt, E.A., Brattain, L., Levea, C., Sun, F.L., Keane, D.M., Gibson, N.W. and Brattain, M.G., 2009. Knockdown of Ron kinase inhibits mutant phosphatidylinositol 3-kinase and reduces metastasis in human colon carcinoma. J Biol Chem 284, 10912-22.

Wang, M.H., Kurtz, A.L. and Chen, Y., 2000. Identification of a novel splicing product of the RON receptor tyrosine kinase in human colorectal carcinoma cells. Carcinogenesis 21 , 1507-12. 
Wang, M.H., Montero-Julian, F.A., Dauny, I. and Leonard, E.J., 1996. Requirement of phosphatidylinositol-3 kinase for epithelial cell migration activated by human macrophage stimulating protein. Oncogene 13, 2167-75.

Wortinger, M., Liu,L., 2008. RON splice variant prevalence in human tumors AACR Annual Meeting-- Apr 12-16, 2008; San Diego, CA

Xu, X.M., Wang, D., Shen, Q., Chen, Y.Q. and Wang, M.H., 2004. RNA-mediated gene silencing of the RON receptor tyrosine kinase alters oncogenic phenotypes of human colorectal carcinoma cells. Oncogene 23, 8464-74.

Zhou, D., Pan, G., Zheng, C., Zheng, J., Yian, L. and Teng, X., 2008. Expression of the RON receptor tyrosine kinase and its association with gastric carcinoma versus normal gastric tissues. BMC Cancer 8, 353.

Zhou, Y.Q., Chen, Y.Q., Fisher, J.H. and Wang, M.H., 2002. Activation of the RON receptor tyrosine kinase by macrophage-stimulating protein inhibits inducible cyclooxygenase-2 expression in murine macrophages. J Biol Chem 277, 38104-10.

Zhou, Y.Q., He, C., Chen, Y.Q., Wang, D. and Wang, M.H., 2003. Altered expression of the RON receptor tyrosine kinase in primary human colorectal adenocarcinomas: generation of different splicing RON variants and their oncogenic potential. Oncogene 22, 186-97.

.


numbers are given for each exon. D: cDNA obtained from different cell lines were PCR amplified using pairs of primers covering increasing lengths RON cDNA sequence. The agarose gel 357 showing fragment sizes above the wells. Results indicate the presence of increasing number of transcripts with increasing amplicon size for each of the cell lines. of RON cDNA from cell line H661 sequenced from 3' end showing deletion of exon 11. The only splicing variant in the sequencing chromatogram, as seen from peak heights, lacked 147 nucleotides, from 2650 to 2796 , corresponding to exon 11 (minor peaks in this sequencing chromatogram were not analyzed) of RON reference cDNA sequence.

Figure 3. Splicing variants lacking exon 11 and exons 11-13 from cell line H249. PCR amplification product of RON cDNA from cell line $\mathrm{H} 249$ sequenced from $5^{\prime}$ end showing the exons 11-13. Exon 10 of the major variant (based on peak heights) ends with TTTGAG sequence, while the same exon ends with TTT in the minor variant due to the skipping of nucleotides GAG.

371 product of cell line H1993 sequenced from 3' end showing the presence of alternatively spliced

372 transcript variant formed due to deletion of exons 11-13.

\section{Figure 5. Differential splicing of exon 10 in RON transcripts of H1993. RON cDNA PCR}

374 product of cell line H1993 sequenced from 5' end showing inclusion of nucleotides CAG at the

375 beginning of exon 10 when compared to reference RON sequence. During the formation of 376 reference RON transcript, CAG, which was part of the intron was spliced out. 
379

380

381

382

383

384

385

386

387

388

389

390

391

392

393

394

395

396

397

$398 \quad$ Figure 1 

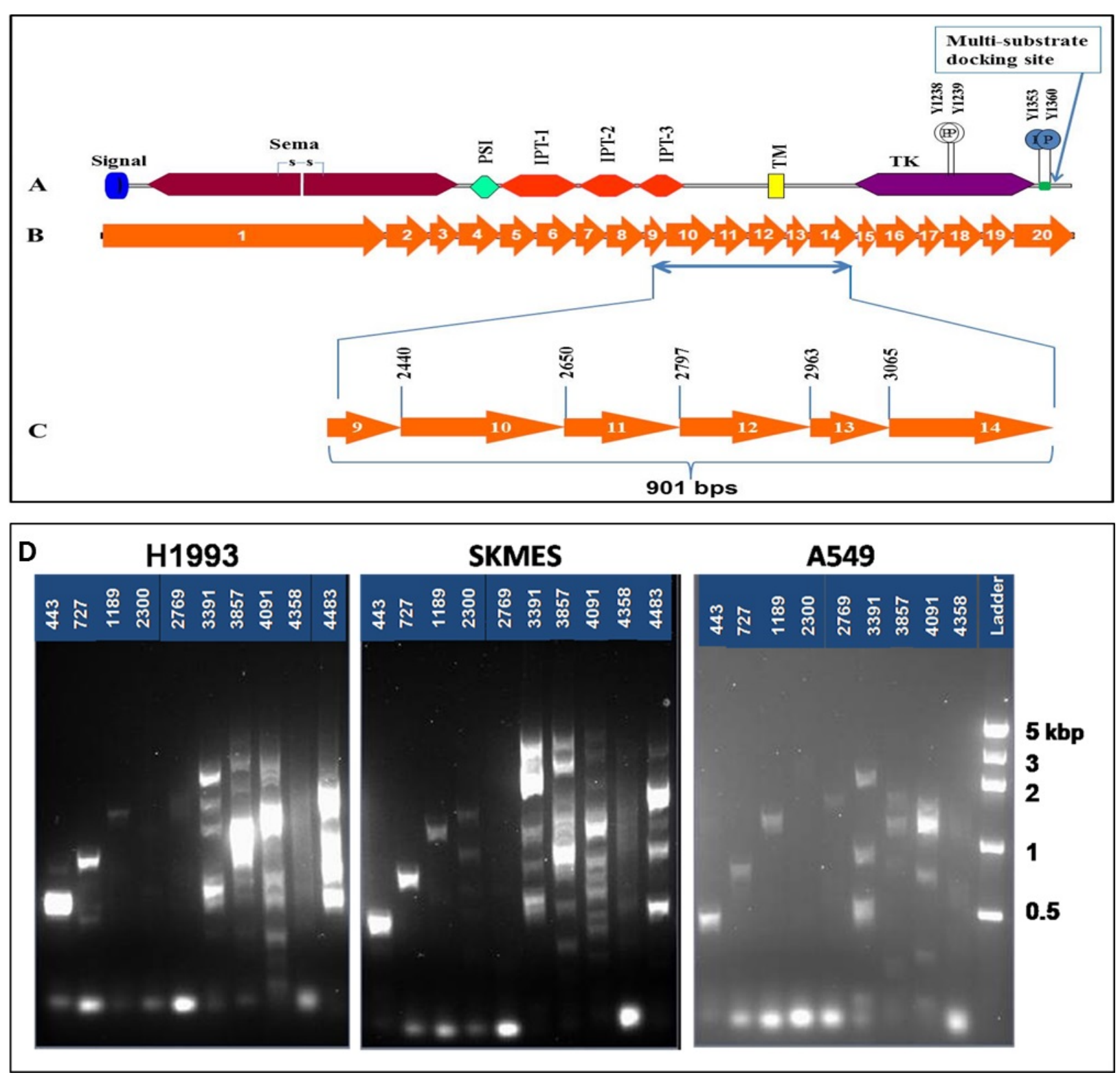

400

401

402

403

404

405

Figure 2 


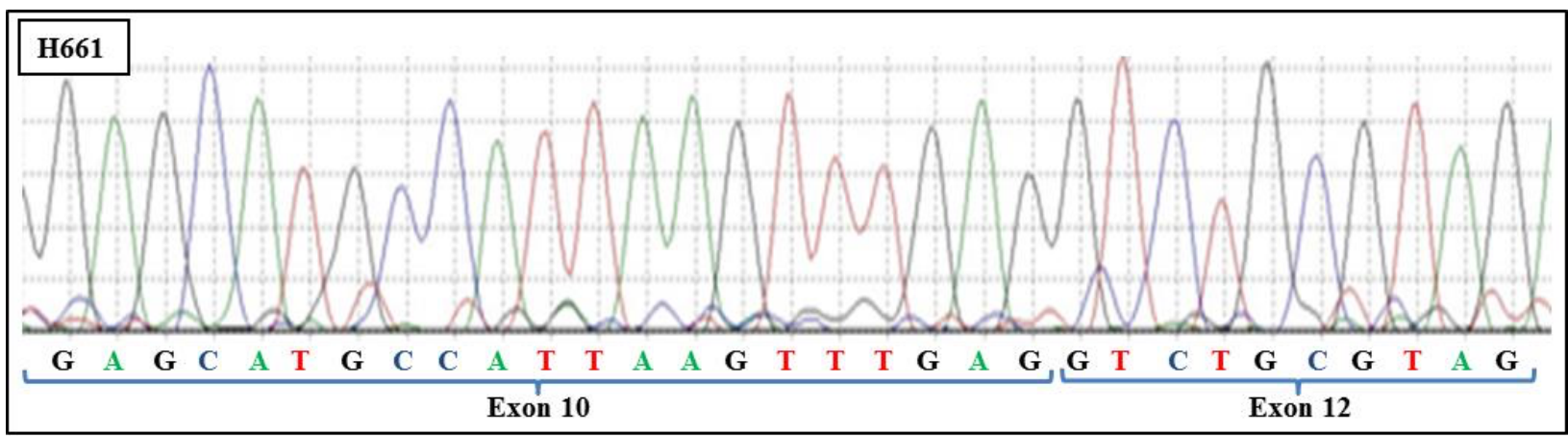

407

Figure 3

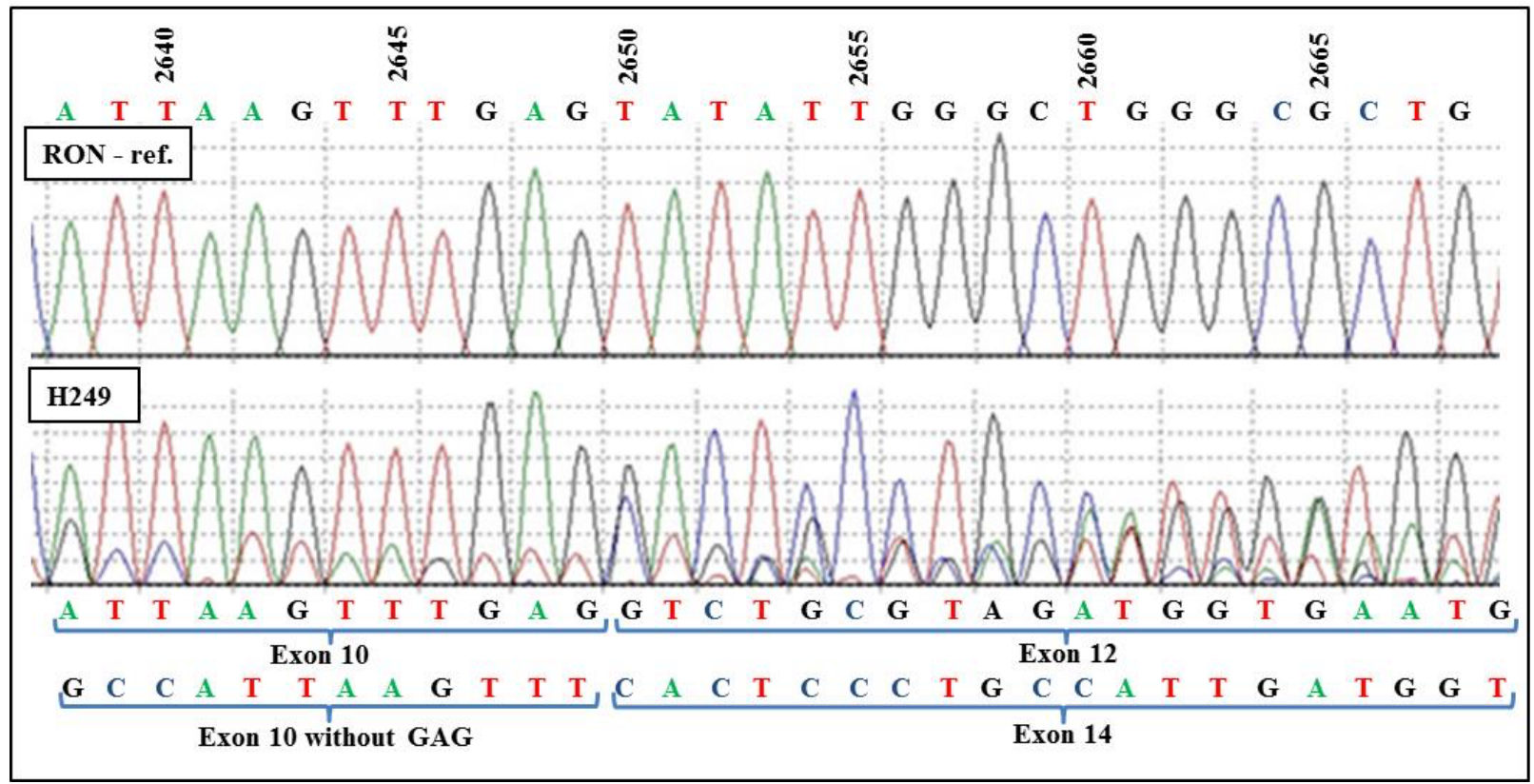

409

410

411

412

413

414

Figure 4 


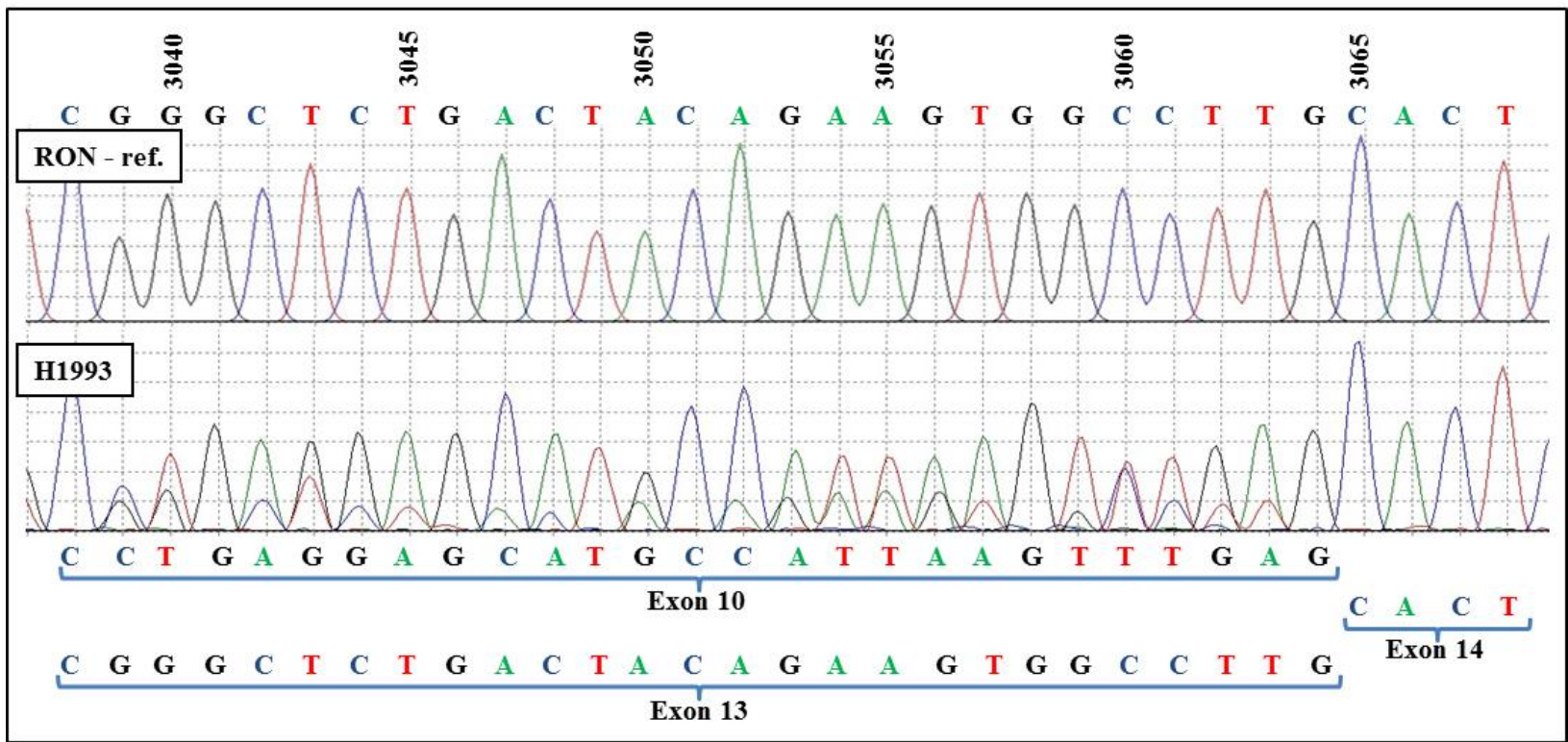

416

417

Figure 5

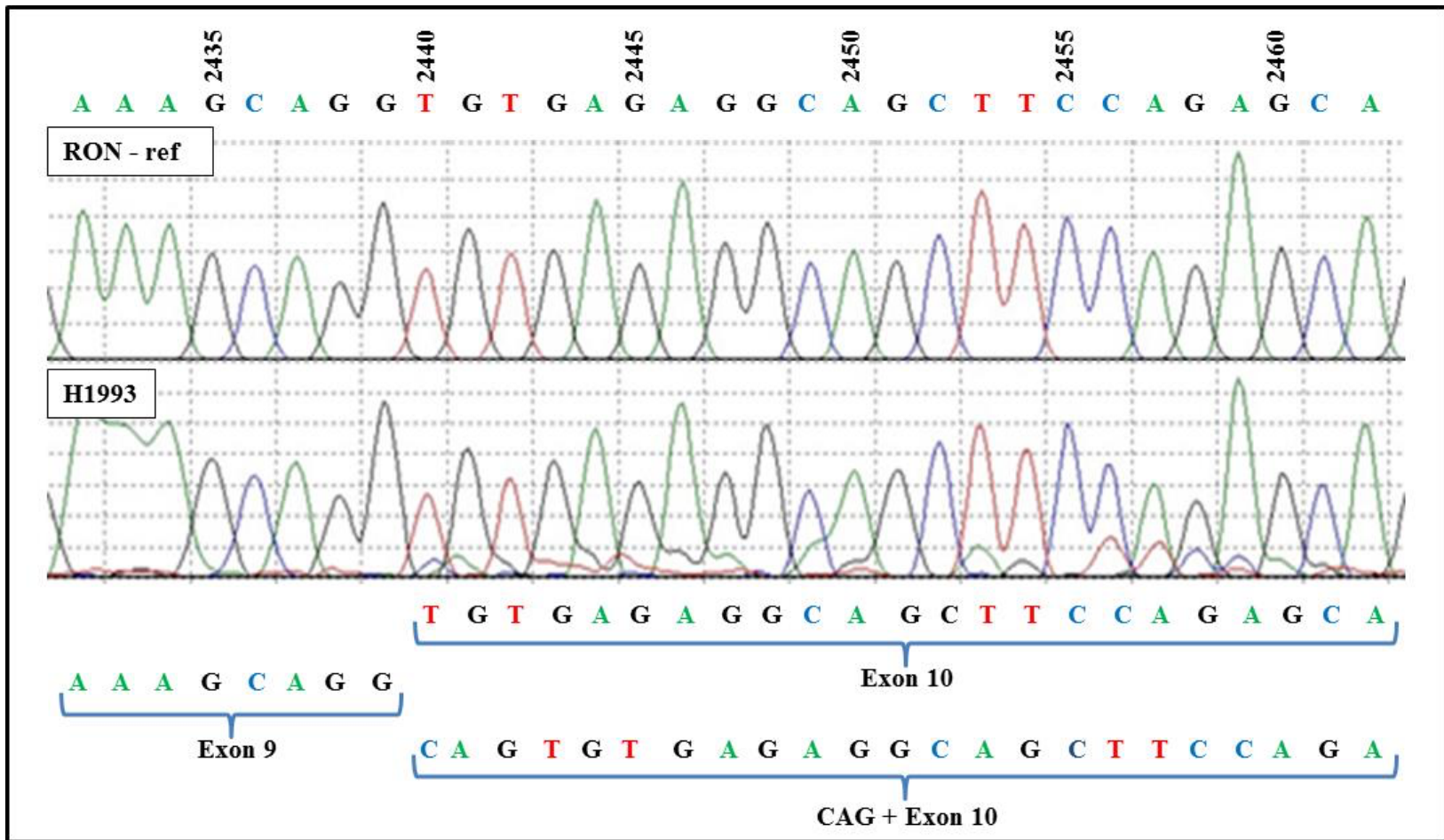

